Gayet Valls, Javier.

Estudiante de doctorado, Universitat Politècnica de València.

\title{
Los orígenes adolescentes del selfie contemporáneo y su representación en el arte.
}

\author{
TIPO DE TRABAJO \\ Comunicación. \\ PALABRAS CLAVE \\ Adolescentes, autorretrato, fotografía digital, redes sociales, selfie. \\ KEY WORDS \\ Adolescents, self portrait, digital photography, social networks, selfie.
}

RESUMEN

Hemos vivido un principio de siglo en el que las reglas del juego han cambiado en lo que a fotografía y producción fotográfica se refiere, debido en parte a la democratización de los actuales dispositivos electrónico-digitales de captura fotográfica y al desarrollo de las redes virtuales como espacios expositivos o de publicación. Asimismo, la proliferación de novedosas y diferentes formas de autorretrato dentro del medio cibernético, nos plantea nuevos paradigmas formales, conceptuales y definitorios vinculados a la historia de la imagen y a la teoría del arte.

El selfie, definido como autorretrato fotografiado con un dispositivo digital para su posterior (o instantánea) publicación en la Red, no es en absoluto un hecho aislado o un género puntual y arbitrario. Son cientos de miles las fotografías que se producen y publican diariamente en todo el mundo siguiendo las premisas y normas que el propio fenómeno dicta: fotografías sujetas a unos cánones compositivos, estéticos y formales que concluyen en una inabordable imaginería de rostros y cuerpos autorepresentados. Actualmente, este tipo de imágenes se han convertido en algo cultural, fomentando la propia transformación evolutiva del medio fotográfico (e incluso sirviendo, con su marcada iconicidad, como marco referencial para diversas representaciones en ámbitos ajenos: el arte, el entretenimiento audiovisual o la publicidad). No obstante, su génesis no fue tan popular, sino el fruto de una creación experimental e íntima vinculada a autoras adolescentes que, encerradas en sus cuartos de baño, se autofografiaban con una cámara compacta en la mano a través de su reflejo en el espejo.

\section{ABSTRACT}

We have live in a turn of the century in which the rules of the game have changed as far as photography and photographic production is concerned, due in part to the democratization of existing electronic devices, digital photo capture and development of the Internet as space exhibition or publication. Likewise, the proliferation of new and different forms of self-portrait in the cyber-virtual environment, raises a new formal, conceptual and definitional paradigm linked to the history of the image or art theory.

The selfie, which we define here as self portrait photographed with a digital device for the later (or snapshot) publication on the Internet, is by no means an isolated or genre specific and arbitrary. Hundreds of thousands of photographs produced and published daily around the world following these assumptions and rules that novel means and tools, in part, dictate: Photographs subject to canons of composition, aesthetic and formal conclude in a unapproachable imagery of faces and bodies self-represented. Currently, this type of images have become a cultural object, promoting own evolutionary transformation of the photographic medium (and even serving, with its strong iconicity, as a framework for various performances in another outside areas: art, audiovisual entertainment or advertising). However, its genesis was not so popular, but the result of an experimental and intimate creation linked to adolescents authors who, locked in their bathrooms, were photographed with a compact camera in hand through her reflection in the mirror. 


\section{CONTENIDO}

Dios mueve al jugador, y éste, la pieza. ¿Qué Dios

detrás de Dios la trama empieza [...]?

JORGE LUIS BORGES, Ajedrez (Poema), 1960

\section{EL SELF SHOT ADOLESCENTE Y SU INFLUENCIA EN EL SELFIE CONTEMPORÁNEO}

Comenzamos a investigar en 2009 la tímida y relativamente reciente aparición de un tipo de imagen fotográfico-digital exhibida en el territorio de Internet, y que por aquel entonces había sido bautizada como self shot por la comunidad de usuarios de esta Red. Nos motivó escoger este (por aquel entonces poco visible) objeto fotográfico como tema de estudio no solo por sus posibilidades y por su complejidad, sino también por la relación íntima y representativa en relación con los nuevos retos a los que se estaba (y se está) enfrentando la fotografía en los primeros años de nuestro nuevo milenio.

Basándonos en el material redactado por el anonimato colectivo de Internet, definimos al self shot como un "autorretrato fotográficodigital publicado en la Red de manera voluntaria o involuntaria". Una actividad que era practicada por aquel entonces, y casi en exclusiva, por jóvenes adolescentes, en su mayoría mujeres. El dispositivo de captura digital (democratizado por cultura y coste) se convirtió en la herramienta fundamental para el desarrollo de este objeto fotográfico. Dicha máquina aparecía en ocasiones reflejada en un espejo y compartiendo protagonismo con la modelo que, íntima y eróticamente, se autorretrataba encerrada en su cuarto de baño (Imagen 1). En otras ocasiones, esta autofoto era un novedoso ejercicio de encuadre, dictaminado por la longitud del brazo sustentador de la cámara que apuntaba "a ciegas" hacia el rostro (Imagen 2). Posteriormente, estas imágenes eran publicadas indirectamente o autopublicadas por sus autoras en Internet a través de foto-blogs y redes sociales, o compartidas por correo electrónico, multiplicándose y convirtiéndose en públicas aunque partieran, en ocasiones, de lo privado. De este modo, se añadían a un imaginario popular que poco a poco se convirtió en global, fijando una iconografía reconocible y un modelo a seguir.

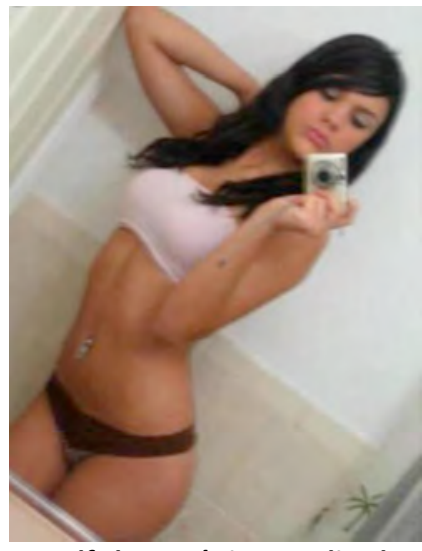

Imagen 1: Self shot anónimo realizado en 2006.

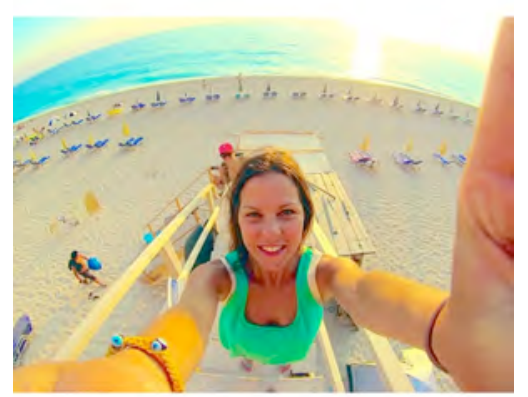

Imagen 2: Self Shot “a ciegas" realizado por Dana Bargielowski en 2013.

\footnotetext{
${ }^{1}$ En aquellos años todavía no existía la lente delantera de los smartphones, que convertía a la pantalla de cristal líquido en un espejo en el
} 
La herencia de este tipo de imágenes producidas desde hace años por el colectivo adolescente, se hace patente en el (recientemente mediático) selfie contemporáneo ${ }^{2}$, practicado de manera masiva por todo tipo de población a lo largo del globo. Su crecimiento entre las masas de casi cualquier condición poblacional no ha sido solo debido al contagio icónico de estos autorretratos producidos durante la década pasada tras la llegada de las comunidades que propició la Web 2.0 participativa, la democratización de las cámaras digitales compactas y de la emancipación fotográfica de los adolescentes. También ha sido fruto del desarrollo de los smartphones (que unificaron herramienta de captura fotográfica y dispositivo de publicación conectado a la Red), de la App de microblogging basado en la imagen Instagram y de la explosión mediática del término selfie que se desató, de manera exponencial, a principios de 2014 tras la 86a edición de los Premios Óscar, en Estados Unidos. El famoso Selfie de los Óscar realizado por Bradley Cooper y tuiteado por la presentadora de la gala Ellen DeGeneres se convirtió en el tuit ${ }^{3}$ con mayor impacto de la historia (Imagen 3 ). Aunque esta popularización masiva del término y su uso había comenzado meses antes, durante 2013, momento en el que, entre otros acontecimientos, la palabra selfie se convirtió en la palabra del año para el Diccionario en inglés de Oxford tras una investigación de idioma realizada por los editores de los Diccionarios Oxford que reveló que la frecuencia de la palabra selfie en el idioma inglés aumentó en un $17.000 \%$ durante el año anterior ${ }^{4}$.

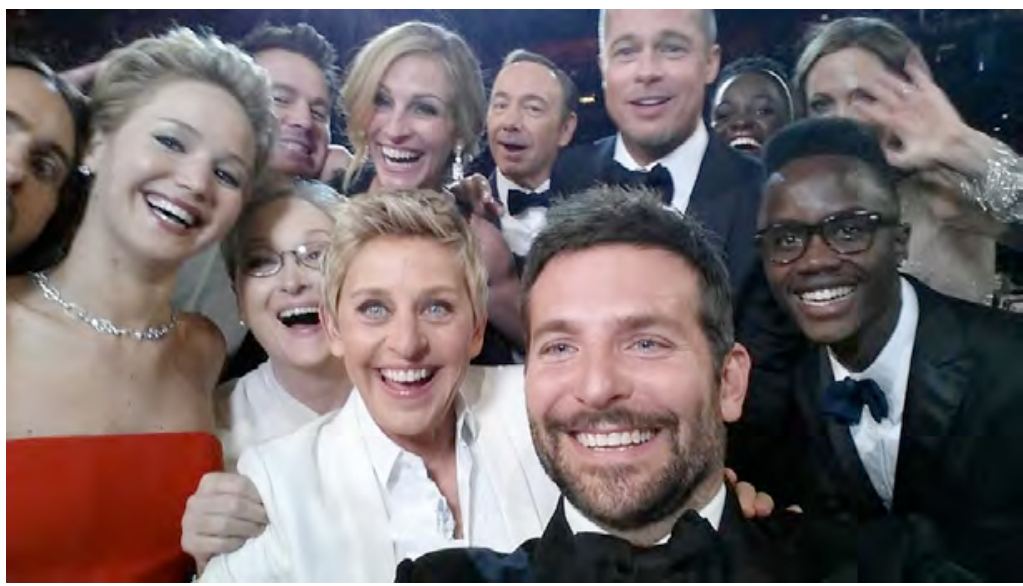

Imagen 3: El mediatizado "Selfie de los Oscar"

Sin embargo, y pese al desarrollo tecnológico y social y al estallido mediático que ha animado a todo tipo de público a realizar masivamente este tipo de prácticas fotográficas, nuestra investigación se centra desde hace años en estudiar los orígenes de este fenómeno y de su impacto icónico en otros ámbitos. Fenómeno que ha sido fruto de la creatividad y del atrevimiento de ese colectivo de mujeres adolescentes: las primeras selfshoters. Ellas acuñaron durante la década pasada un modelo que poco a poco se hizo visible. Rompieron la primera capa de hielo, luego pasó todo lo demás.

\section{LA MUSEIFICACIÓN DEL SELFIE}

Al margen de que el selfie ha servido y sirve como marco referencial para realizar todo tipo de representaciones, como en cine, la publicidad, los videojuegos, y otros tantos campos del desarrollo de la imagen (Imagen 4), nos centraremos ahora brevemente en algunos ejemplos de self shots y selfies museificados o de simulaciones de selfies que han sido asociadas exclusivamente a la esfera artística por medio de una práctica expositiva. Son, básicamente, ejemplos de artistas que también han incluido en su trayectoria proyectos que pueden estar vinculados con este elemento icónico del autorretrato frente a un espejo (tipo mirrorpic ${ }^{5}$ ) o del autorretrato de cámara girada (con disparo "a ciegas" o mediante la pantalla espejo, tipo selfie), y que lo han exhibido con los protocolos habituales del artista que muestra expositivamente su obra.

\footnotetext{
${ }^{2}$ Selfie al que el anonimato de la comunidad-Internet ofrece una definición similar a la que ofrecía al self shot: "autorretrato fotográficodigital publicado en la Red". Aunque se trata de ejercicios similares, presentan diferencias, aunque en forma pueden llegar a estar solapados en la mayoría de ocasiones, de hecho su terminología suele confundirse. No obstante el término selfie se ha popularizado tanto, que actualmente la palabra self shot ha quedado en desuso.

${ }_{4}^{3}$ El tuit original puede verse en <https://twitter.com/theellenshow/status/440322224407314432> [Fecha de consulta: 20 de julio de 2014].

${ }^{4}$ Noticia en castellano en <http://mexico.cnn.com/salud/2013/11/19/selfie-se-convierte-en-la-palabra-en-ingles-del-ano-para-oxford>

[Fecha de consulta: 24 de julio de 2014].

${ }^{5}$ El mirrorpic es un tipo de self shot o de selfie en el que la persona se autorretrata mediante su reflejo en un espejo. Quedan enmarcados en la fotografía el modelo y el dispositivo, ya que lo que se fotografía es el reflejo, como hemos visto en la primera imagen.
} 

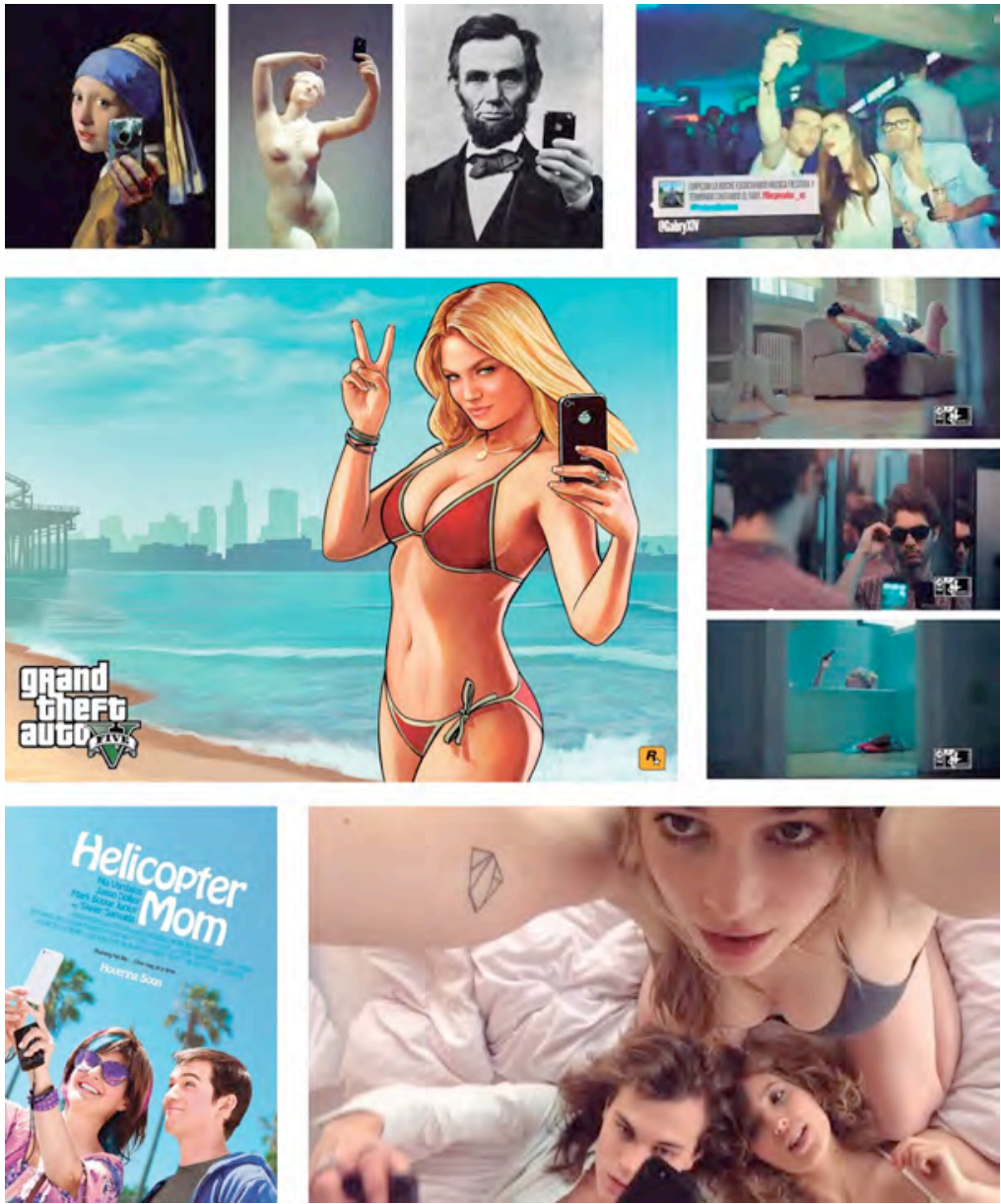

Imagen 4: Conjunto de imágenes, en orden de lectura de cómic: Tres chistes visuales gráficos, 2012-2014; Videoclip que hace también las veces de spot publicitario para Desperados, 2013; Imágen gráfica publicitaria para el videojuego Grand Theft Auto $V$ de Rockstar Games, 2013; 3 capturas de un Spot publicitario de Mahou, 2013; Cartel para la película "Helicopter Mom", de Salomé Breziner, 2015; Por último, un frame de la producción audiovisual realizada por Mario Sorrenti para la campaña publicitaria de Calvin Klein, ck one, bajo el slogan "me for me", 2014: una erótica apuesta acerca de la manera que tienen los jóvenes de autoregistrar y hacer públicos sus escenarios privados y que nos recuerda a la iconografía desarrollada por Natacha Merritt (a la que consideramos una de las pionera del self shot íntimo y erótico) 15 años antes.

En primer lugar cabe destacar las autorrepresentaciones terapéuticas de Cristina Núñez, una artista que trabaja su propia representación fotográfica mediante autorretratos frente al espejo. Si bien actualmente trabaja con medios digitales y publica sus imágenes en Internet, sus primeras obras fueron realizadas antes del desarrollo de la Red y de la democratización de las cámaras digitales. Estas primeras obras eran mirrorpics avant la lettre (Imagen 5). Y lo eran en forma y en metodología, aunque en este caso, su motivación fuera diferente a la de las adolescentes que, durante la primera década del siglo XXI (como hemos repasado antes) iniciaran esta cadena global y masiva de autorrepresentación popular publicada en la Red: y es que Cristina Núñez empezó a realizar estos autorretratos fotográficos en 1988 como terapia para superar problemas de autoestima que le habían hecho drogodependiente durante su juventud. Sus prácticas eran, pues, ejercicios de proyección hacia el mundo de su anteriormente deteriorado yo. Las mismas daban forma a sus emociones y permitían establecer una lectura de sí misma, consolidándose como un método de cura. Más tarde, y completamente recuperada, realizará ejercicios de reflexión y denuncia a través de su propia imagen, como este autorretrato que dialoga sobre el holocausto judío en Mauthausen (Imagen 6). En la actualidad, Cristina continúa realizándose autorretratos frente a espejos (Imagen 7). Además, imparte talleres de autorrepresentación fotográfica para adultos, bajo el apelativo The Self Shot Experience ${ }^{6}$, uniendo así arte y terapia. Su objetivo es que sus alumnos, al igual que ella hizo, conviertan sus emociones en obras de arte por medio del autorretrato fotográfico 7 .

\footnotetext{
${ }^{6}$ Web del proyecto en: <http://www.self-portrait.eu/home/> [Fecha de consulta: 12 de febrero de 2015].

${ }^{7}$ Hay una recopilación publicada en 2013 de material audiovisual de Cristina Núñez en relación a su desarrollo y a sus proyectos en DOMÍNGUEZ, Chus y SOLÁ, Belén, "El trabajo sobre autobiografía de Cristina Núñez", disponible en: <http://raraweb.org/el-trabajo-sobre-autobiografia-de-cristina-nunez.html> [Fecha de consulta: 16 de julio de 2014].
} 


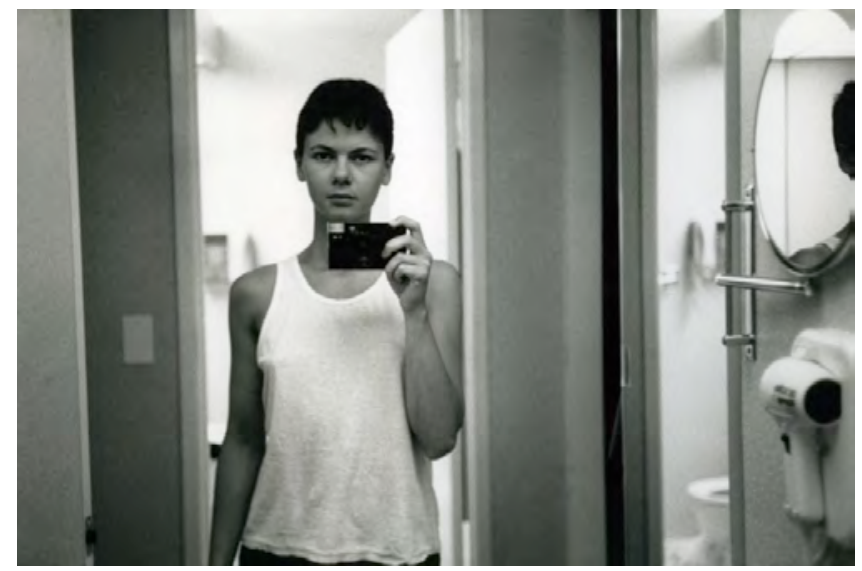

Imagen 5: Cristina Núñez, Autorretrato, 1988.

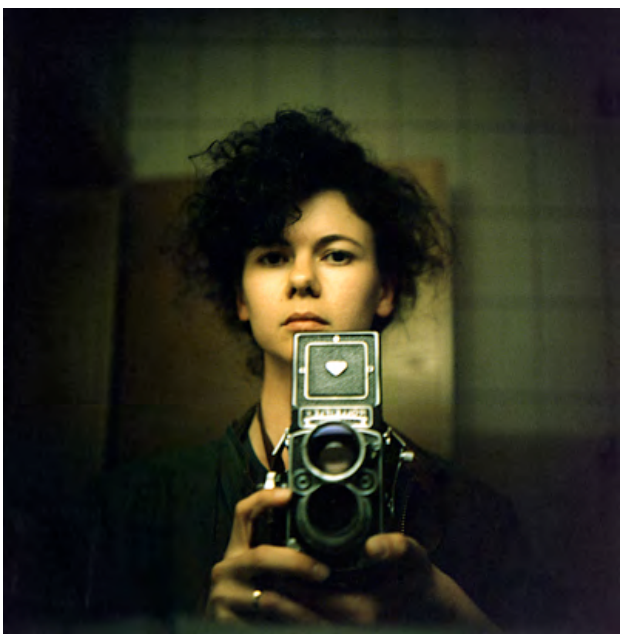

Imagen 6: Cristina Núñez, Mauthausen, 1995.

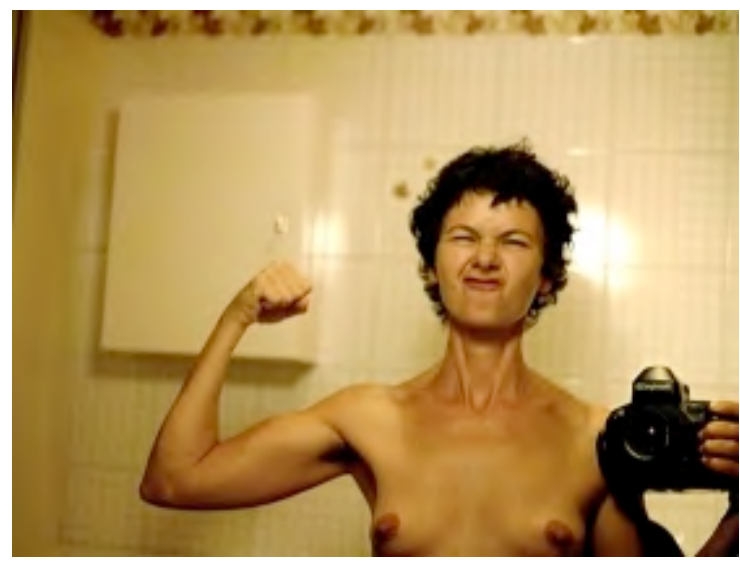

Imagen 7: Cristina Núñez, My Mamiya es my medicine, 2008.

Si bien toda la obra de Cristina Núñez gira en torno al autorretrato de espejo, otras artistas como Tete de Alencar ${ }^{8}$ realizan proyectos específicos dentro de su trayectoria cuyos aspectos formales pueden recordarnos a los de la marcada imaginería del mirrorpic adolescente. Tete es una artista afincada en Londres, que ha realizado entre 2005 y 2012 un proyecto expositivo relacionado con la fotografía y la performance, y que responde al título de Cinderella Flash (Imagen 8). Esta serie se compone de un número de fotografías de gran formato que representan a la artista mediante su autorretrato, realizado con la cámara en la mano y siempre frente al espejo de un probador. El flash del dispositivo nubla su cara, desde donde dispara, pero podemos apreciar el resto de su

\footnotetext{
${ }^{8}$ Web de la artista: <http://www.tetedealencar.com/> [Fecha de consulta: 16 de julio de 2014].
} 
cuerpo luciendo vestidos de fiesta de corte princesa. Esta serie realizada en probadores de Londres, París o Nueva York (capitales de la moda) pretende ser una crítica a la sociedad de consumo, y ha sido expuesto en diferentes salas ${ }^{9}$.

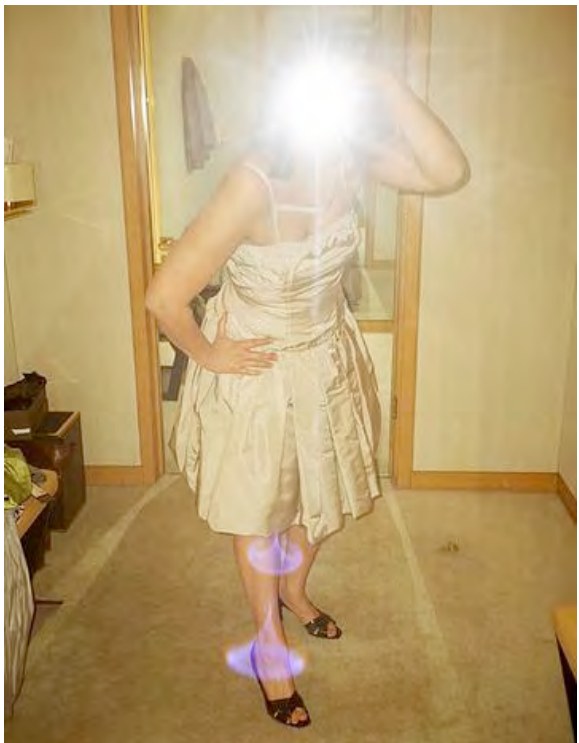

Imagen 8: Tete de Alencar, Cinderella Flash, entre 2005 y 2012, fotografía, 160 x $80 \mathrm{~cm}$.

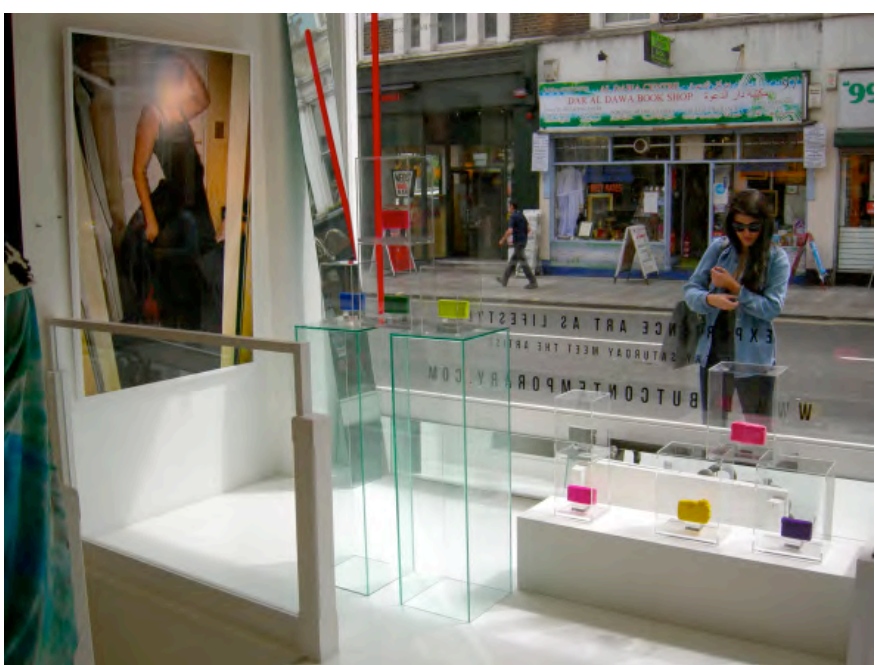

Imagen 9: Fotografía desde el interior de la galería de arte Debut Contemporary de Londres en 2011.

El teórico y artista Joan Fontcuberta, cuyos textos están muy presentes en nuestros artículos e investigaciones (ya que ha sido de los pocos en reconocer y escribir de manera muy temprana acerca del fenómeno self shot y de su continuación en el selfie), también en varios de sus proyectos expositivos ha utilizado como referencia (y como objeto) el autorretrato digital adolescente desarrollado durante la década pasada. De hecho no utiliza los principios compositivos y formales de estos objetos fotográficos como una doctrina para practicar la autorrepresentación en nuevas imágenes, sino que va mucho más allá: emplea los propios self shots encontrados en los espacios públicos de la Red como ingredientes con los que construir la obra. Son su materia prima. Una de estas exposiciones fue $A$ través del espejo que se pudo visitar en Barcelona durante la feria de fotografía e imagen Sonimagfoto y Multimedia $2011^{10}$. En ella, Fontcuberta mostraba más de 3000 autorretratos de espejo o mirrorpics que circulaban a través de multitud de proyectores con intervalos de 2 segundos (Imagen 10). A su vez, también hizo reproducciones de estos autorretratos sobre papel, que junto con las proyeccciones, y a modo de instalación, generaban discursos que tenían que ver con la construcción de la identidad del individuo en

\footnotetext{
${ }^{9}$ Por ejemplo, en la galería de arte Debut Contemporary de Londres en 2011 (Imagen 9) o en el Museu Valencià de la II·lustració i la Modernitat (MuVIM) en 2013.

${ }^{10}$ Hay muchas noticias en los medios que narran la exposición de este artista, entre ellas, la del diario La vanguardia: VERA, Carlos y COLLAZOS, Carlos, "Joan Fontcuberta provoca en Sonimag", 2011, disponible en:

<http://videos.lavanguardia.com/20110325/54132752234/joan-fontcuberta-provoca-en-sonimag.html> [Fecha de consulta: 16 de julio de 2014].
} 
las redes sociales y con la visibilización de este tipo de prácticas fotográficas que tan difíciles son de encontrar fuera de su propio medio. Por otro lado, la propia naturaleza de la exposición facilitó el debate acerca de los derechos de imagen en la era de Internet y del uso que se puede o no hacer de ellas: muchos de los autorretratos eran desnudos de jóvenes que seguramente nunca sabrán que sus cuerpos formaron parte de esa exposición pública (aunque no debería importunarles, ya que esas mismas imágenes ya eran públicas en un espacio expositivo mucho más vasto y visible: Internet). Al margen de todos los (a nuestro parecer) interesantes discursos que generó esta exposición de Fontcuberta, también sirvió para evidenciar, mediante esta vasta acumulación tipológica, que el objeto de estudio diseccionado en nuestro artículo, ya era (y lo era desde hace tiempo) un objeto fotográfico practicado y producido de manera masiva durante años por el tipo de autores al que nos hemos referido anteriormente: los adolescentes y jóvenes que se empeñaron en generar esa iconografía que en 2011, momento de la exposición, ya podría ser recolectable y recopilable.

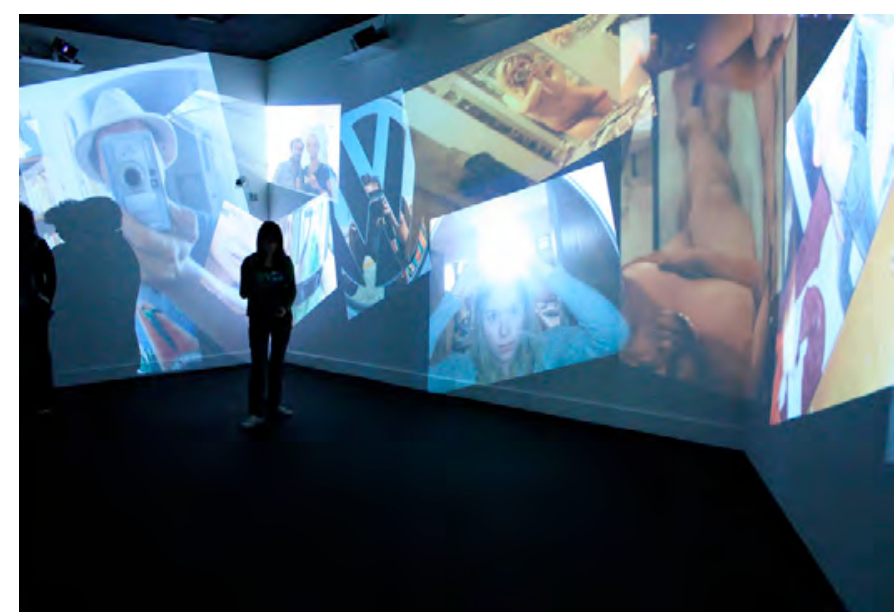

Imagen 10: Instalación de Joan Fontcuberta, dentro de su exposición A través del espejo.

También queremos revisar el trabajo de una autora que, si bien pertenece a un ámbito más modesto y menos mediático de la esfera artística, entendemos que su obra tiene una curiosa y pertinente importancia respecto al enfoque aplicado en este artículo y en nuestra investigación: se trata de la joven fotógrafa madrileña Lucía del Carmen Luque Rodríguez, que en 2011, y con tan solo 14 años de edad, expuso su obra Esa soy yo (Imagen 11), seleccionada para la exposición 2010, retratos de una generación, en la que participaban adolescentes de 14 a 18 años, todos alumnos estudiantes de lengua francesa en colegios y liceos españoles ${ }^{11}$. Dicha muestra se pudo ver del 3 de marzo al 1 de abril de 2011 en la sala de exposiciones del Instituto Francés de Valencia. Entre las fotos de los participantes había trabajos de diversa índole: todos apuntaban a diferentes maneras de representar la juventud de la época, pero Lucía fue la única que utilizó las formalidades del mirrorpic como estrategia para autorrepresentarse y poder establecer el discurso fotográfico. La fotografía que mostró era un mirrorpic al uso. Nada más que añadir, por tanto, salvo el curioso guiño casi metonímico que supuso este tipo de ejercicio en una exposición planteada bajo la temática de la auto-visión adolescente. También destacar la útil explicación de la obra que se narraba en una cartela bajo la misma pieza: "Pienso que esta fotografía es parte de la generación 2010, ya que representa a la juventud de hoy en día y a la adolescencia". Gracias Lucía.

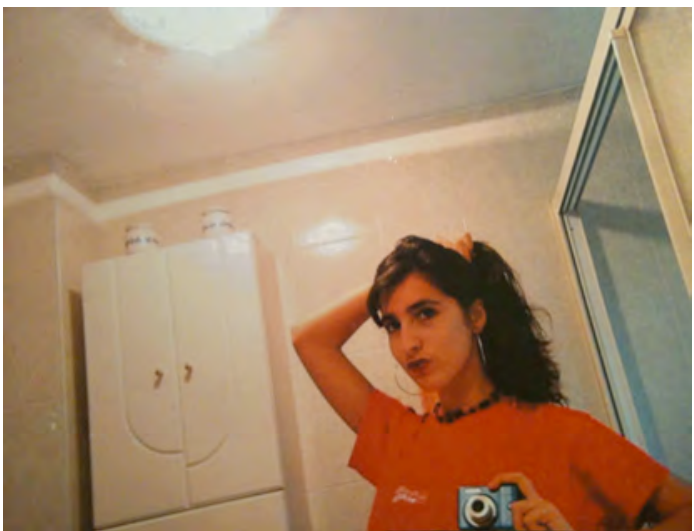

Imagen 11: Lucía del Carmen Luque Rodríguez, Esa soy yo, 2010.

\footnotetext{
${ }^{11}$ La noticia puede localizarse en la edición digital del periódico El País: AUNIÓN, Juan Antonio, "Una generación retratada por sí misma", 2009, disponible en:

<http://sociedad.elpais.com/sociedad/2009/12/02/actualidad/1259708416 850215.html> [Fecha de consulta: 19 de julio de 2014].
} 
Además de esta presentación de self shots y selfies museificados como elementos puramente fotográficos, vamos a revisar ahora y brevemente algunos otros ejemplos que, si bien no son autorretratos fotográfico-digitales, si que se han basado en su iconicidad y forma para desarrollar su representación en otros ámbitos plásticos como pueda ser el dibujo o la pintura: citamos en primer lugar al artista Juan Francisco Casas ${ }^{12}$, reconocido por su obra de dibujos a bolígrafo de pequeño y gran formato. En su exposición "(A)Utopic", realizada en la Galería Fernando Pradilla de Madrid en $2014^{13}$, pudo verse una selección de dibujos que no son sino las representaciones (en forma de dibujo) de mirrorpics íntimos y eróticos enviados al artista por mujeres selfshoters de todo el mundo (Imágenes 12 y 13). También utilizaremos dos ejemplos más, en esta ocasión expuestos en el ámbito de la pintura: los artistas Sierk van Meeuwen y Wenli Liu. Las dos obras que aquí incluimos (Imágenes 14 y 15) constituyen ejemplos que igualmente ponen de manifiesto el uso de esta imaginería ya asentada formal y culturalmente y utilizada, como luego veremos, también en otros medios.
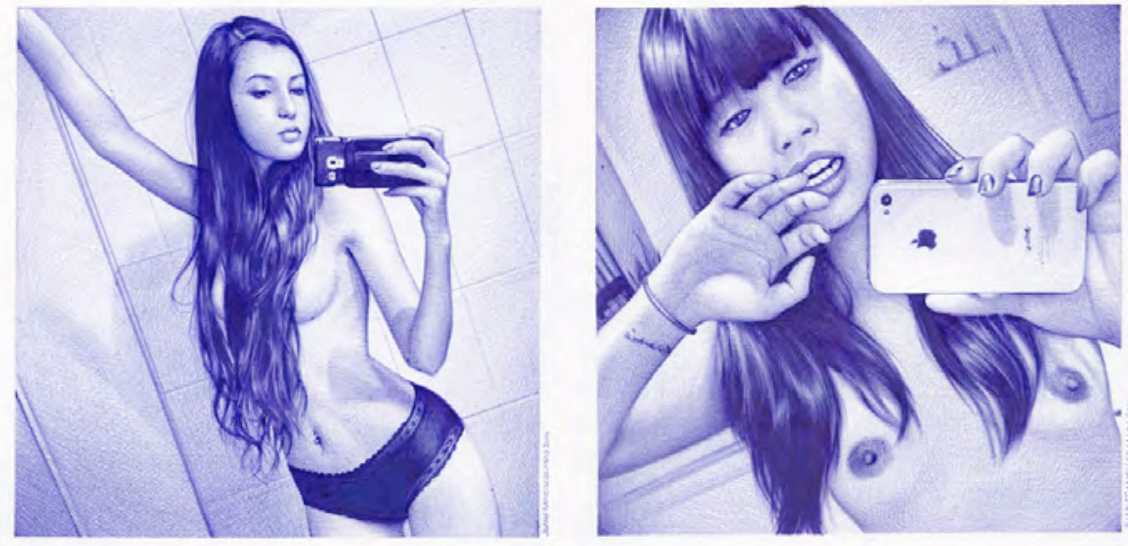

Imagen 12 (izquierda): Juan Francisco Casas, Ana Sofía/Guadalajara/México\#3, 2014, Bolígrafo sobre papel, 15 x $15 \mathrm{~cm}$. Imagen 13 (derecha): Juan Francisco Casas, Aisa/Tokorozawa/Japan\#1, 2014, Bolígrafo sobre papel, 15 x $15 \mathrm{~cm}$.
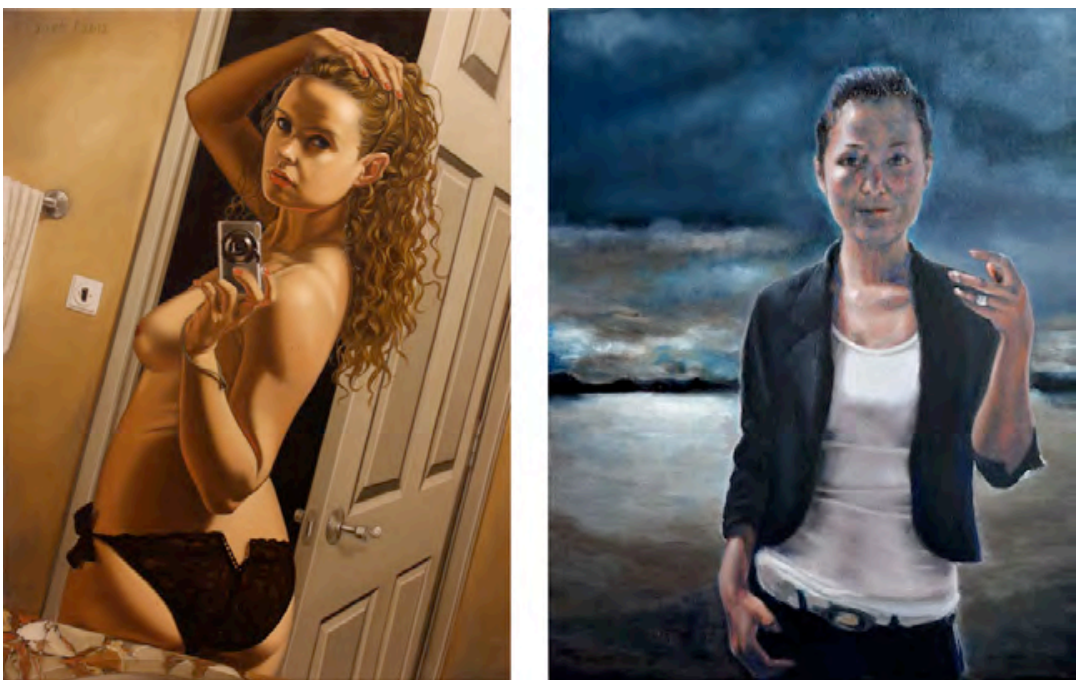

Imagen 14 (izquierda): Sierk van Meeuwen, Self shot no2, 2012, óleo sobre lienzo, 40 x $30 \mathrm{~cm}$. Imagen 15 (derecha): Wenli Liu, Self shot At Dusk, 2013, óleo sobre lienzo, 71 x 56 cm.

Por último, nombraremos un par de proyectos que, si bien no han sido expuestos en los ámbitos del museo, la galería o en cualquier otro espacio físico e institucionalizado de exposición artística tradicional, sí que han tenido una amplia relevancia como objetos museísticos mostrados en cualquiera de las plataformas virtuales que proporciona la Red: por ejemplo el proyecto Selfiecity ${ }^{14}$, que investiga la forma y el estilo de una cantidad de selfies realizados por los habitantes de cinco ciudades del mundo: Bangkok, Berlín, Moscú, Nueva York y Sao Paulo. Aunque a primera vista se trata de una recopilación de imágenes expuestas en la Red, Selfiecity

\footnotetext{
${ }^{12}$ Su obra puede verse en la página web de la artista: <http://www.juanfranciscocasas.com/> [Fecha de consulta: 19 de abril de 2015]

${ }^{13}$ Una reseña a la exposición de este artista puede consultarse, por ejemplo, en PAC, Plataforma de Arte Contemporáneo: GARCíA, Óscar, "Selfies para Juan Francisco Casas", 2014, disponible en:

<http://www. plataformadeartecontemporaneo.com/pac/selfies-para-juan-francisco-casas/> [Fecha de consulta: 21 de abril de 2015].

${ }^{14}$ La web del proyecto y sus resultados pueden consultarse en: <http://selfiecity.net/> [Fecha de consulta: 24 de abril de 2015].
} 
(Imagen 16) también es un proyecto de investigación ${ }^{15}$ que analiza datos y obtiene conclusiones mediante el estudio de estos autorretratos $^{16}$. Y destacamos también por (a nuestro entender) su importante relevancia dentro de las claves que intentamos enumerar en nuestra investigación, el interesante e inquietante proyecto de autorretrato diario, "The Adaption to My Generation", que desarrolla desde 1998 el artista estadounidense Jonathan Keller Keller ${ }^{17}$ (Imagen 17).

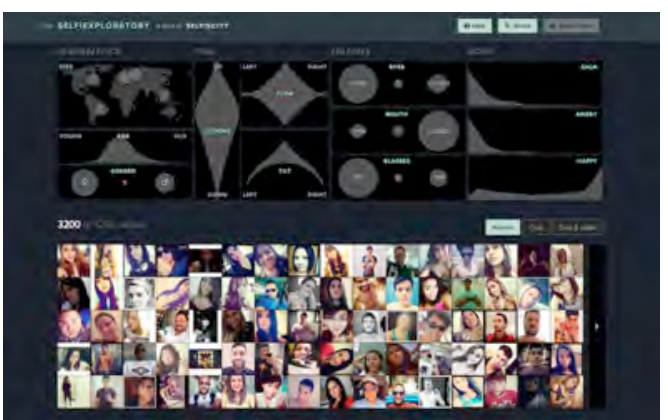

Imagen 16: Algunos datos y Selfies del proyecto Selfiecity.

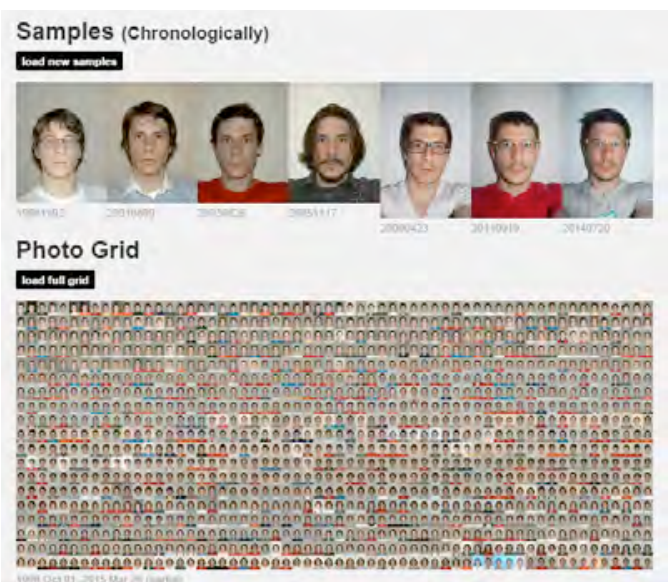

Imagen 17: Selfies del proyecto “The Adaption to My Generation” de JK Keller mostrados en su página web.

Estos son ejemplos que ponen de manifiesto que el selfie puede llegar a ser museificado en cualquier tipo de espacio físico o virtual, no obstante, y al igual que ocurre con el graffiti trasladado al interior de la galería de arte, no aportará nada más a la idiosincrasia general del fenómeno, salvo quizá, una mayor visibilidad. Pensamos que el selfie y sus variantes ya tienen su espacio de germinación natural: la Red. Se trata de un objeto completo en sí mismo, no necesita ser trasladado a esferas más artísticas o institucionales para dotarle de un valor existencial o de una fortificación mayor de la que pueda disponer detrás de sus propias trincheras.

\section{CONCLUSIONES}

Aunque este breve artículo presentado forma parte de un proceso investigador enmarcado en la redacción de una tesis doctoral todavía en desarrollo, podemos aproximarnos al esbozo de algunas conclusiones que valoramos como pertinentes:

Hemos intentado evidenciar el hecho de que el self shot (y su continuidad en el selfie) ha sido y es un fenómeno extendido, en auge y en constante crecimiento. Es una práctica contemporánea que, casi con total certeza, será recordada ya que es fruto de una época. Aunque $a$ priori estas prácticas y sus representaciones pueden parecernos banales y arbitrarias, el selfie es un ejercicio especialmente creativo y, en la mayoría de ocasiones, completamente libre. Un ejercicio que genera productos fotográficos que podemos entender como objetos de investigación e interés estético, y que si bien actualmente son aceptados (tras un auge de popularidad experimentado durante estos últimos años) y practicados por la mayoría de los grupos de población mundial que tengan acceso a este tipo de tecnologías, en su origen fueron creaciones fotográficas exclusivas del colectivo adolescente, emancipado como creador de

\footnotetext{
${ }^{15}$ Liderado por el analista de datos audiovisuales Lev Manovich y en el que participan diseñadores, programadores, teóricos de la comunicación, historiadores de arte y otro tipo de científicos.

${ }^{16}$ Algunas de estas conclusiones, (junto con una breve explicación del proyecto), quedan recogidas en nuestro idioma en el artículo de Yoroboku: CABRIA, Elsa, "Anatomía del selfie", 2014, disponible en:

$<$ http://www.yorokobu.es/anatomia-del-selfie/> [Fecha de consulta: 22 de abril de 2015].

${ }^{17}$ En un apartado de su página web: <http://jk-keller.com/daily-photo/> [Fecha de consulta: 25 de abril de 2015] podemos ver el desarrollo del proyecto, sus imágenes y un time-lapse que muestra, hasta la fecha, el paso del tiempo sobre su rostro a lo largo de 16 años y mediante la sucesión rápida de miles de selfies tomados y publicados por Jonathan a lo largo de los años.
} 
imágenes, y que supo combinar el uso de los entonces novedosos dispositivos de captura fotográfica digital con los espacios cobijados en la Red de publicación y encuentro cibernético-social que comenzaban a operar a mediados de la década pasada. Los adolescentes, en su mayoría mujeres, acuñaron este tipo de modelo o de iconografía propia, generada de manera colectiva mediante su experimentación, divertimento, exhibición y erotismo, y que aproximó la esfera privada a la esfera pública. Entendemos que fueron ellas las pioneras de un modelo (formal en la imagen y metódico en el acto) que terminaría por contagiar al resto de población en todas sus latitudes de edad y condición.

Como hemos visto pues, el selfie goza ya de cierta codificación e imaginería (pese a su relativamente reciente origen) siendo capaz de influir en otros medios que no son el propio, como el arte, la publicidad o el entretenimiento audiovisual. No obstante, su simulación fuera de su medio no deja de ser una artificialidad. El self shot y el selfie han estado y están íntimamente asociados con el ecosistema donde se alojan: el dispositivo fotográfico-electrónico y la Red, lugar donde voyeurs y narcisistas establecen su relación mediante impulsos electrónicos y código binario y espacio donde jóvenes y adultos realizan sus rituales de autorepresentación publicada, en donde acontecimiento y fotografía-publicación de este propio acontecimiento se funden en una misma cosa, en donde también queda impuesta una fórmula (costumbrista y pactada socialmente) de creación de imágenes reconocibles, como hace décadas lo fueron las fotos grupales de turistas frente al monumento de la ciudad visitada.

\section{FUENTES REFERENCIALES}

AA.VV., Estética fotográfica, Barcelona, Gustavo Gili, 2003.

ALBERCA, Manuel, La escritura invisible. Testimonios sobre el diario íntimo, Oyarzun, Sendoa, 2010.

BALTRUSAITIS, Jurgis, El espejo. Ensayo sobre una leyenda científica, Madrid, Miraguano/Polífemo, 1988.

BARTHES, Roland, La cámara lúcida, Barcelona, Paidós Ibérica, 2009.

BERGER, John, Sobre las propiedades del retrato fotográfico, Barcelona, Gustavo Gili, 2006.

BERNERS-LEE, Tim, Tejiendo la red. El inventor del World Wide Web nos descubre su origen, Buenos Aires, Siglo XXI, 2000.

BORNAY, Erika, Las hijas de Lilith, Madrid, Cátedra, 2005.

BOURDIEU, Pierre, Un arte medio, Barcelona, Gustavo Gili, 2003.

BREA, José Luis, Las tres eras de la imagen, Madrid, Akal, 2010.

CONTRERAS, Salvador, La protección del honor, la intimidad y la propia imagen en Internet, Madrid, Aranzadi, 2012.

DEBRAY, Régis, Vida y muerte de la imagen, Historia de la mirada en occidente, Barcelona, Paidós Ibérica, 1998.

DELEUZE, Gilles y GUATTARI, Félix, Rizoma (Introducción), Valencia, Pre-Textos, 1977.

EGUIZÁBAL, Raúl, Fotografía publicitaria, Madrid, Cátedra, 2006.

FAERMAN, Juan, Faceboom: El nuevo fenómeno de masas Facebook, Barcelona, Alienta, 2010.

FONTCUBERTA, Joan, La cámara de Pandora. La fotografi@ después de la fotografía. Barcelona, Gustavo Gili, 2010.

FREUND, Gisèle, La fotografía como documento social, Barcelona, Gustavo Gili, 1998.

GREEN, David, ¿Qué ha sido de la fotografía?, Barcelona, Gustavo Gili, 2007.LINASCHKE, Joseph, Getting the Most from Instagram, San Francisco, Peachpit Press, 2011.

MARZAL, Javier, Cómo se lee una fotografía, Madrid, Cátedra, 2007. 
MELOT, Michel, Breve historia de la imagen, Madrid, Siruela, 2010.

MUÑOZ, Elisa, La seguridad jurídica de los menores en el uso de las redes sociales, Madrid, Editorial Académica Española, 2012.

NEAD, Lynda, El desnudo femenino. Arte, obscenidad y sexualidad, Madrid, Editorial Tecnos, 1998.

SONTAG, Susan, Sobre la fotografía, Barcelona, Debolsillo, 2008.

SOUGEZ, Marie-Loup, Historia de la fotografía, Madrid, Cátedra, 2006.ZAFRA, Remedios, Un cuarto propio conectado. (Ciber)espacio y (auto)gestión del yo, Madrid, Fórcola ediciones, 2010.

ZUNZUNEGUI, Santos, Pensar la imagen, Madrid, Cátedra, 1989. 